\title{
Dissipation Rate Estimates from Microstructure and Finescale Internal Wave Observations along the A25 Greenland-Portugal OVIDE Line
}

\author{
Bruno Ferron, Florian Kokoszka, Herlé Mercier, and Pascale Lherminier \\ Laboratoire de Physique des Océans, UBO-IFREMER-CNRS-IRD, Plouzané, France
}

(Manuscript received 21 February 2014, in final form 28 July 2014)

\begin{abstract}
A total of 96 finestructure and 30 microstructure full-depth vertical profiles were collected along the A25 Greenland-Portugal Observatoire de la Variabilité Interannuelle et Décennale en Atlantique Nord (OVIDE) hydrographic line in 2008. The microstructure of the horizontal velocity was used to calculate turbulent kinetic energy dissipation rates $\varepsilon_{\mathrm{vmp}}$, where vmp refers to the vertical microstructure profiler. The lowest dissipation values $\left(\varepsilon_{\mathrm{vmp}}<0.5 \times 10^{-10} \mathrm{~W} \mathrm{~kg}^{-1}\right)$ are found below $2000 \mathrm{~m}$ in the Iberian Abyssal Plain and in the center of the Irminger basin; the largest values $\left(>5 \times 10^{-10} \mathrm{~W} \mathrm{~kg}^{-1}\right)$ are found in the main thermocline, around the Reykjanes Ridge, and in a 1000 -m-thick layer above the bottom near $48^{\circ} \mathrm{N}$. The finestructure of density was used to estimate isopycnal strain and that of the lowered acoustic Doppler current profiler to estimate the vertical shear of horizontal velocities. Strain and shear were used to estimate dissipation rates $\varepsilon_{\mathrm{G} 03}$ (Gregg et al.) associated with the internal wave field. The shear-to-strain ratio correction term of the finescale parameterization $\varepsilon_{\mathrm{G} 03}$ brings the fine- and microscale estimates of the dissipation rate into better agreement as Polzin et al. found. The latitude/buoyancy frequency term slightly improves the parameterization for weakly stratified waters. Correction term $\varepsilon_{\mathrm{G} 03}$ is consistent with $\varepsilon_{\mathrm{vmp}}$ within a factor of 4.5 over $95 \%$ of the profiles. This good consistency suggests that most of the turbulent activity recorded in this dataset is due to the internal wave field. The canonical globally averaged diffusivity value of order $10^{-4} \mathrm{~m}^{2} \mathrm{~s}^{-1}$ needed to maintain the global abyssal stratification (Munk) is only reached on the flank of the Reykjanes Ridge and in the region around $48^{\circ} \mathrm{N}$.
\end{abstract}

\section{Introduction}

Turbulent mixing plays a key role in the global water mass budget of the ocean and contributes to the maintenance of the stratification. Since turbulent mixing is a key component of the global overturning circulation (Munk and Wunsch 1998) and because of its strong spatial heterogeneity and temporal intermittence, continuous efforts to measure its distribution and magnitude and to understand the underlying mechanisms need to be pursued. Turbulent mixing is usually quantified locally from microstructure data obtained from specific instruments with $O(1 \mathrm{~cm})$ resolution (e.g., Oakey 1982) and from the finestructure data obtained with the widely used conductivity-temperature-depth (CTD) and lowered acoustic Doppler current profilers (LADCP). The finestructure is either used to quantify Thorpe scales

Corresponding author address: Bruno Ferron, Laboratoire de Physique des Océans, IFREMER, Centre de Brest, ZI Pointe du Diable, CS 10070, 29280 Plouzané, France.

E-mail: bruno.ferron@ifremer.fr
(Thorpe 1977; Dillon 1982) or to diagnose the intensity of the internal wave field (Gregg 1989). At larger scales, turbulent mixing can also be quantified from tracer release experiments and from tracer budgets (e.g., Ledwell et al. 1993, 2000; Hogg et al. 1982). During the last decade, an increasing number of studies used the finescale properties of the internal wave field to quantify turbulent mixing due to the internal wave environment (e.g., Hibiya and Nagasawa 2004; Naveira Garabato et al. 2004a,b; Walter et al. 2005; Kunze et al. 2006; Lauderdale et al. 2008; Stöber et al. 2008; MacKinnon et al. 2008; Daae et al. 2009; Tian et al. 2009). Other studies have compared and validated the local approaches based on microstructure, which contains mixing from different mechanisms, and finescale parameterizations (Gregg 1989; Polzin et al. 1995; Gregg et al. 2003; Hibiya et al. 2012; Frants et al. 2013; Sheen et al. 2013; Waterman et al. 2013) based on the internal wave field, which is presumed to be a major contributor of ocean interior mixing.

In this paper we present full-depth dissipation rate profiles obtained with a vertical microstructure profiler along the A25 Greenland-Portugal Observatoire de la 
Variabilité Interannuelle et Décennale en Atlantique Nord (OVIDE) hydrographic line and compare them to finescale parameterizations of the dissipation rate based on internal wave-wave interaction theory. We tested several parameterizations of the dissipation rate, which depends on finescale observations of internal wave velocity shear and strain, by comparing them with dissipation data. Gregg (1989) proposed a shear-based parameterization for the turbulent dissipation rate:

$$
\varepsilon_{\mathrm{G} 89}=\varepsilon_{0}\left(\frac{N}{N_{0}}\right)^{2} \frac{\left\langle V_{z}^{2}\right\rangle^{2}}{\left\langle V_{z \mathrm{GM}}^{2}\right\rangle^{2}},
$$

where $\varepsilon_{0}=7 \times 10^{-10} \mathrm{~W} \mathrm{~kg}^{-1}$, and $N / N_{0}$ and $\left\langle V_{z}^{2}\right\rangle /\left\langle V_{z \mathrm{GM}}^{2}\right\rangle$ being the buoyancy frequency and the shear variance, respectively, scaled by their respective values from the Garrett and Munk (GM) model (Garrett and Munk 1975; Cairns and Williams 1976). This parameterization has been subsequently refined by several authors. To better represent regions that depart from the canonical GM description, Polzin et al. (1995) incorporated a frequency correction $h$ leading to a new parameterization, defined as

$$
\varepsilon_{\mathrm{P} 95}=\varepsilon_{\mathrm{G} 89} h\left(R_{\omega}\right),
$$

where

$$
h\left(R_{\omega}\right)=\frac{3}{4}\left(1+\frac{1}{R_{\omega}}\right) \sqrt{\frac{2}{R_{\omega}-1}},
$$

and $R_{\omega}=\left\langle V_{z}^{2}\right\rangle /\left(N^{2}\left\langle\zeta_{z}^{2}\right\rangle\right)$ is the shear $\left(V_{z}\right)$-to-strain $\left(\zeta_{z}\right)$ variance ratio. Gregg et al. (2003) added a term $j$ dependent on latitude to improve the consistency with the dissipation rates found in the equatorial region that are weaker than at midlatitudes. Gregg et al.'s (2003) parameterization reads

$$
\varepsilon_{\mathrm{G} 03}=\varepsilon_{\mathrm{P} 95} j(f / N),
$$

where

$$
j(f / N)=\frac{f \cosh ^{-1}(N / f)}{f_{30} \cosh ^{-1}\left(N_{0} / f_{30}\right)},
$$

where $f$ is the inertial frequency and $f_{30}=f\left(30^{\circ}\right)$. Following Wijesekera et al. (1993), internal wave shear variance ratios in those parameterizations can be replaced by internal wave strain variance ratios (e.g., Kunze et al. 2006), leading to

$$
\varepsilon_{\zeta}=\varepsilon_{0}\left(\frac{N}{N_{0}}\right)^{2} \frac{\left\langle\zeta_{z}^{2}\right\rangle^{2}}{\left\langle\zeta_{z \mathrm{GM}}^{2}\right\rangle^{2}} h_{\zeta}\left(R_{\omega}\right) j(f / N),
$$

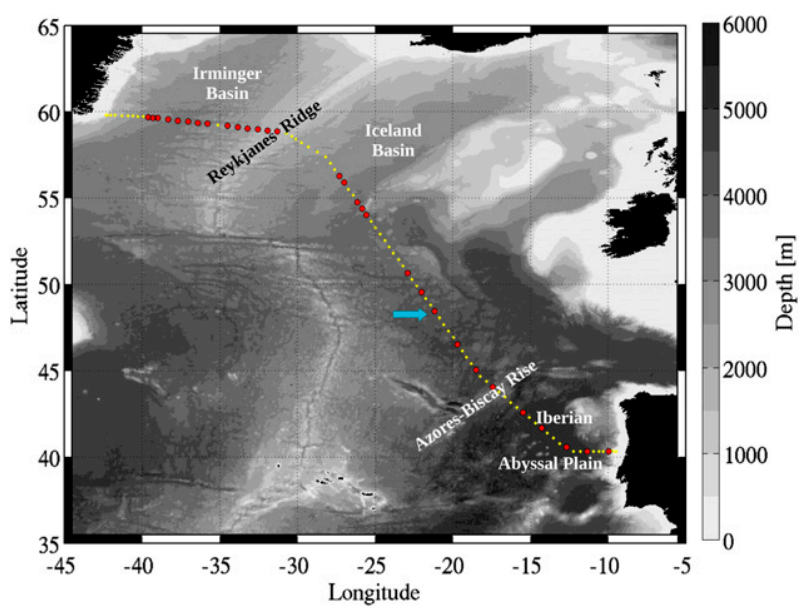

FIG. 1. Position of CTD-LADCP stations (yellow and red dots) and VMP stations (red dots) along the A25 OVIDE hydrographic line. The blue arrow indicates a station $\left(48^{\circ} 02^{\prime} \mathrm{N}, 20^{\circ} 51^{\prime} \mathrm{W}\right)$ with enhanced dissipation rates at depth (topography from Smith and Sandwell 1997).

where

$$
h_{\zeta}\left(R_{\omega}\right)=\frac{R_{\omega}\left(R_{\omega}+1\right)}{6 \sqrt{2\left(R_{\omega}-1\right)}} .
$$

In the following we present evaluations of $\varepsilon_{\mathrm{G} 89}, \varepsilon_{\mathrm{P} 95}$, and $\varepsilon_{\mathrm{G} 03}$, and compare them with dissipation rates measured with a microstructure profiler along the OVIDE transect that spans both a large latitudinal band $\left(40^{\circ}-59^{\circ} \mathrm{N}\right.$; Fig. 1) and a large range of buoyancy frequencies from $1.6 \times 10^{-4} \mathrm{~s}^{-1}$ to $3.2 \times 10^{-3} \mathrm{~s}^{-1}$.

\section{Dataset}

The OVIDE project consisted of repeating the A25 Greenland-Portugal hydrographic line every 2 years from 2002 to 2010 (Mercier et al. 2014). Each survey was composed of nearly 100 CTD-LADCP profiles (Fig. 1, yellow and red dots). Measurements lasted 3 weeks usually in June/July. During 2008, an autonomous vertical microstructure profiler (VMP; www.rocklandscientific.com) able to dive to $6000 \mathrm{~m}$ was deployed at 30 CTD locations (Fig. 1, red dots). The geographical distribution of the VMP deployments was not as uniform as that of the CTD. In particular, no VMP stations were done on either the southeastern flank of the Reykjanes Ridge because of heavy sea conditions or on the Greenland continental slope because of a technical problem with the instrument. The VMP was deployed 20-30 min before the CTD cast began and about half a nautical mile away from the CTD station location to avoid any collision. The VMP was retrieved after the end of the CTD 
upcast. The VMP was programmed before deployment to stop its profile $70 \mathrm{~m}$ above the bottom, while the CTD-LADCP profiles were stopped $10-15 \mathrm{~m}$ above the bottom.

\section{a. Microstructure data}

The VMP is a 3 -m-long instrument that weights $150 \mathrm{~kg}$. Microstructure sensors are located at the bottom of the instrument, so that only data from the downcast are useful. On the OVIDE cruise, the typical downcast fall rate of the instrument was $0.7 \mathrm{~m} \mathrm{~s}^{-1}$, a velocity high enough to apply Taylor's frozen turbulence hypothesis, which allows a conversion from time to space using a smoothed instrument fall speed profile.

The VMP carried two Rockland Scientific fast thermistors (FP-07), one Sea-bird Electronics (SBE) microconductivity sensor (SBE-7), and two Rockland Scientific velocity shear probes (SPM-38). Microstructure channels were sampled at $512 \mathrm{~Hz}$. A low-pass ana$\log$ filter with a cutoff frequency of $165 \mathrm{~Hz}$ was applied on all microstructure channels to avoid aliasing.

Data from the two shear probes were used to calculate dissipation rates. The first $10 \mathrm{~m}$ of the dissipation profiles were discarded, since data were frequently contaminated by ship wake. In this study, fast thermistors and microconductivity data were only used to visually check the turbulence signal given by the shear probes. Shear data were first edited to remove spikes. Assuming isotropy, the dissipation rate of turbulent kinetic energy per unit mass reads $\varepsilon=7.5 \nu\left\langle u_{z}^{2}\right\rangle$, where $\nu$ is the viscosity of seawater and $u_{z}$ is the vertical shear of the horizontal velocity $u$. The velocity shear variance $\left\langle u_{z}^{2}\right\rangle$ was estimated by a spectral analysis of the velocity shear signals. The velocity shear spectra were calculated using halfoverlapping 512-point segments. Each segment was linearly detrended and windowed with a Hanning taper function prior to FFT calculation. Spectral coherence between the velocity shear data and the three accelerometer data was used to remove vibrational contamination (Levine and Lueck 1999; Goodman et al. 2006). Because of their finite size, velocity shear probes tend to average the smallest turbulent eddies, thereby underestimating shear variance at high wavenumbers (Oakey 1982). Velocity shear spectra were corrected for velocity shear probe averaging using a single-pole filter for the wavenumber response of the probe with a cutoff wavenumber of 48 cycles per meter (cpm; Macoun and Lueck 2004). To obtain velocity shear variance, shear spectra were integrated up to a cutoff wavenumber $k_{c}$ found iteratively. The procedure followed that described by Moum et al. (1995). For the first iteration, $k_{c}$ was set to $15 \mathrm{cpm}$ and gave a first dissipation rate estimate from which the Kolmogorov wavenumber $k_{s}=(2 \pi)^{-1}\left(\varepsilon / \nu^{3}\right)^{1 / 4}$

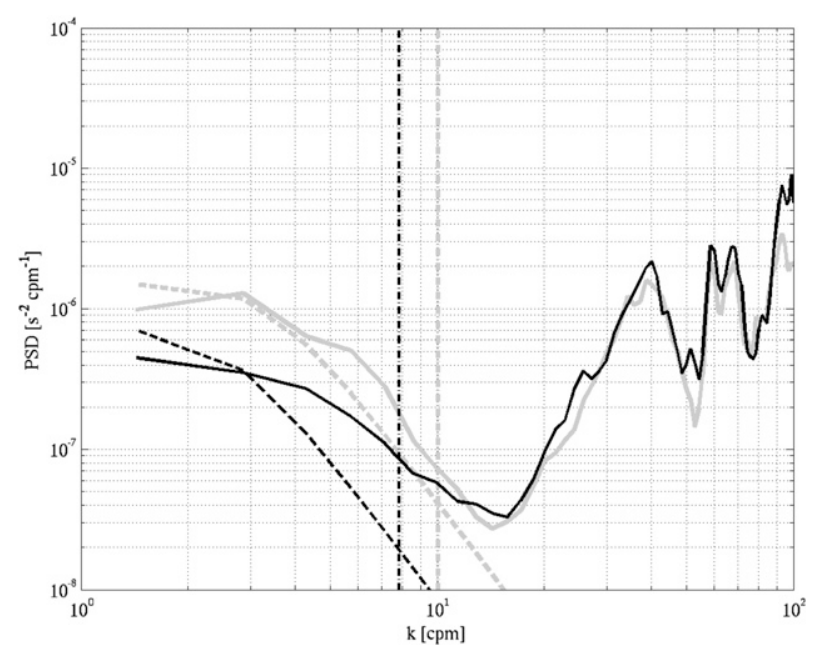

FIG. 2. Example of an average of four PSD of microstructure velocity shear (solid) observed with the VMP for the profile located at $42^{\circ} 35^{\prime} \mathrm{N}, 15^{\circ} 27^{\prime} \mathrm{W}$ and at a depth of 4200 (gray) and $4270 \mathrm{~m}$ (black). Dashed curves are matching Nasmyth (1970) spectra for $\varepsilon=7.2 \times 10^{-11} \mathrm{~W} \mathrm{~kg}^{-1}$ (gray) and for $\varepsilon=2.6 \times 10^{-11} \mathrm{~W} \mathrm{~kg}^{-1}$ (black). Vertical lines give the corresponding Kolmogorov wavenumber.

was estimated. For the next iteration, $k_{c}$ was increased to $k_{s}$ or, to avoid noise contamination at high wavenumbers, to a maximum of $50 \mathrm{cpm}$. The Kolmogorov wavenumber was then updated. The iterative process was stopped when the relative difference between $k_{c}$ and $k_{s}$ was lower than $0.001 \%$, or when $k_{c}$ was equal to $50 \mathrm{cpm}$ or after 10 iterations. At the end of the iteration process, if $k_{c}<k_{s}$, then velocity shear variance loss was accounted for assuming Nasmyth (1970) turbulence spectrum form. The background noise on the dissipation rate profile was set to $5 \times 10^{-11} \mathrm{~W} \mathrm{~kg}^{-1}$. It was estimated from quiescent profiles of the deep ocean located in the Iberian Abyssal Plain. Following Gregg (1999) criteria, we observed that for dissipation rates lower than $5 \times$ $10^{-11} \mathrm{~W} \mathrm{~kg}^{-1}$, spectra of microstructure velocity shear tend to depart from Nasmyth spectra. Examples of microstructure velocity shear spectra calculated at two different depths are provided as an illustration for a profile located at $42^{\circ} 35^{\prime} \mathrm{N}, 15^{\circ} 27^{\prime} \mathrm{W}$ (Fig. 2). While the spectrum followed the Nasmyth spectral shape at a depth of $4200 \mathrm{~m}$ and for a dissipation rate of $7.2 \times$ $10^{-11} \mathrm{~W} \mathrm{~kg}^{-1}$ (Fig. 2, gray curves), it clearly departed from the Nasmyth spectral shape at a depth of $4270 \mathrm{~m}$ for a dissipation rate of $2.6 \times 10^{-11} \mathrm{~W} \mathrm{~kg}^{-1}$ (Fig. 2, black curves). Note that for those two examples, power spectral density (PSD) rise was due to the presence of noise for wavenumbers larger than $13 \mathrm{cpm}$. This does not influence the dissipation rate estimate though, since Kolmogorov wavenumbers (viscous cutoff wavenumber) that set the upper bound of the spectral integration in the 
dissipation rate calculation are lower than $13 \mathrm{cpm}$ (Fig. 2, vertical black and gray lines).

\section{b. Finestructure data}

On the OVIDE 2008 cruise, one upward-looking $300-\mathrm{kHz}$ and one downward-looking $150-\mathrm{kHz}$ RD Instruments workhorse LADCPs mounted on the CTD carousel provided observations of vertical shear of horizontal currents with 16-m vertical resolution. LADCP data were processed with the velocity-inversion method initially developed by Visbeck (2002).

To compute the velocity shear variance, each velocity profile was split into $640-\mathrm{m}$ segments with $75 \%$ overlap. Each segment was linearly detrended prior to FFT calculation. Buoyancy-normalized shear variance was calculated as the integral, from the lowest wavenumber $k_{\min }=2 \pi / 640 \mathrm{rad} \mathrm{m}^{-1}$ up to a maximum wavenumber $k_{\max }$ determined for each segment, of the velocity spectra $S(u)$ multiplied by a transfer function $T(k)$ (see discussion below): $\left\langle u_{z}^{2}\right\rangle=\int_{k_{\min }}^{k_{\max }} k^{2} S(u) T(k) d k$, where $k_{\max }$ is the minimum of $k_{\text {noise }}$ and $k_{c}, k_{\text {noise }}$ is the wavenumber above which noise dominates the signal (see discussion below), and $k_{c}$ is the cutoff wavenumber for which the integrated velocity shear variance equals 0.66 $\overline{N^{2}}$, where $\overline{N^{2}}$ is the segment-averaged buoyancy frequency. The GM velocity shear spectra were also integrated from $k_{\min }$ to $k_{\max }$. Finding $k_{c}$ for which $\left\langle u_{z}^{2}\right\rangle=0.66 \overline{N^{2}}$ (i.e., the variance of the GM velocity spectra integrated up to its cutoff wavenumber of $2 \pi /$ $10 \mathrm{~m}^{-1}$ ) takes into account the fact that the cutoff wavenumber decreases with increasing energy level in the shear (Polzin et al. 1995; Gregg et al. 2003).

Polzin et al. (2002) showed that spectral corrections $T(k)$ need to be applied to compensate for loss of velocity variance at a wavelength shorter than about $200 \mathrm{~m}$ because of the various steps of the acquisition and processing methods of the LADCP data. While Polzin et al. (2002) processed their LADCP data using the shear method (Firing and Gordon 1990; Fischer and Visbeck 1993), Thurnherr (2012) updated the spectral corrections for the velocity-inversion method and showed that it naturally produces less damping at short wavelengths. With the velocity-inversion method, the shear spectra need to be corrected at least for range averaging and depth binning. A supplementary term arises when data are prebinned into superensembles before the inversion, as done for our dataset. When instrument tilting is important, an additional term also applies. Considering the weak averaged tilt (mean tilt angle of $1.8^{\circ}$ ) due to our carousel configuration, no tilt correction was applied in this study. As Polzin et al. (2002) suggested, beam separation effects were ignored. Spectral correction for our data processing then takes the form of the transfer

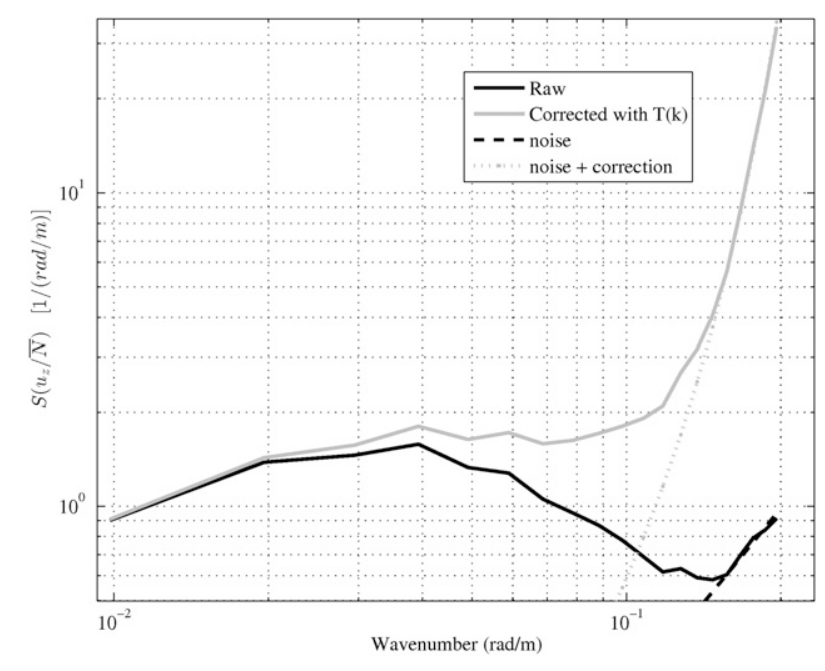

FIG. 3. Comparison of ensemble-averaged buoyancy-normalized shear spectra without (raw) and with the use of the transfer function $T(k)$ (see text). The ensemble was made of 589 spectra in the depth range $96-2656 \mathrm{~m}$ and from longitude $10^{\circ}-25^{\circ} \mathrm{W}$ and latitude $40^{\circ}-52^{\circ} \mathrm{N}$.

function $T(k)=\operatorname{sinc}^{8}[k \Delta z /(2 \pi)]$, where $k$ is the vertical wavenumber and $\Delta z=16 \mathrm{~m}$ represents the ADCP transmit pulse length, range gate length, superensemble preaveraging interval, and bin length of the output grid. An illustration of an ensemble-averaged raw (uncorrected) velocity shear spectrum scaled by the buoyancy frequency and its corrected version is given for an ensemble of profiles that were taken away from steep bathymetry, so that we expected a relatively flat spectral shape close to that of the GM model (Fig. 3). The ensemble was made of 589 spectra in the depth range 96$2656 \mathrm{~m}$, from longitude $10^{\circ}$ to $25^{\circ} \mathrm{W}$ and from latitude $40^{\circ}$ to $52^{\circ} \mathrm{N}$. In this example, the raw spectrum falls off by $60 \%$ from wavenumbers $0.04 \mathrm{rad} \mathrm{m}^{-1}$ (wavelengths of $160 \mathrm{~m}$ ) to wavenumbers $0.1 \mathrm{rad} \mathrm{m}^{-1}$ (wavelength of $60 \mathrm{~m}$ ). Such a damping is typical of the velocity-inversion method (see Thurnherr 2012, his Fig. 1). After correction, the spectral shape is relatively flat up to wavenumbers close to $0.1 \mathrm{rad} \mathrm{m}^{-1}$, above which noise dominates.

Ensemble-averaged shear spectra clearly show a depth-dependent contamination by noise at high wavenumbers for which the rms noise $S_{\text {rms }}$ strongly dominates the signal (Fig. 4a). To estimate the increase in the single-ping error $S_{\text {err }}$ depth, a fit to the high wavenumber part of each spectrum is done, which provides the rms noise $S_{\text {rms. }}$. The number of averaged pings $N_{\text {pings }}$ into each superensemble varies as a function of depth, since the carousel was stopped more frequently to close Niskin bottles when getting to shallower depth during the upcast (Table 1$)$. The single-ping error $\left[S_{\text {err }}=\right.$ $\left.S_{\text {rms }}\left(N_{\text {pings }}\right)^{1 / 2}\right]$ increased with depth from $0.06 \mathrm{~m} \mathrm{~s}^{-1}$ 

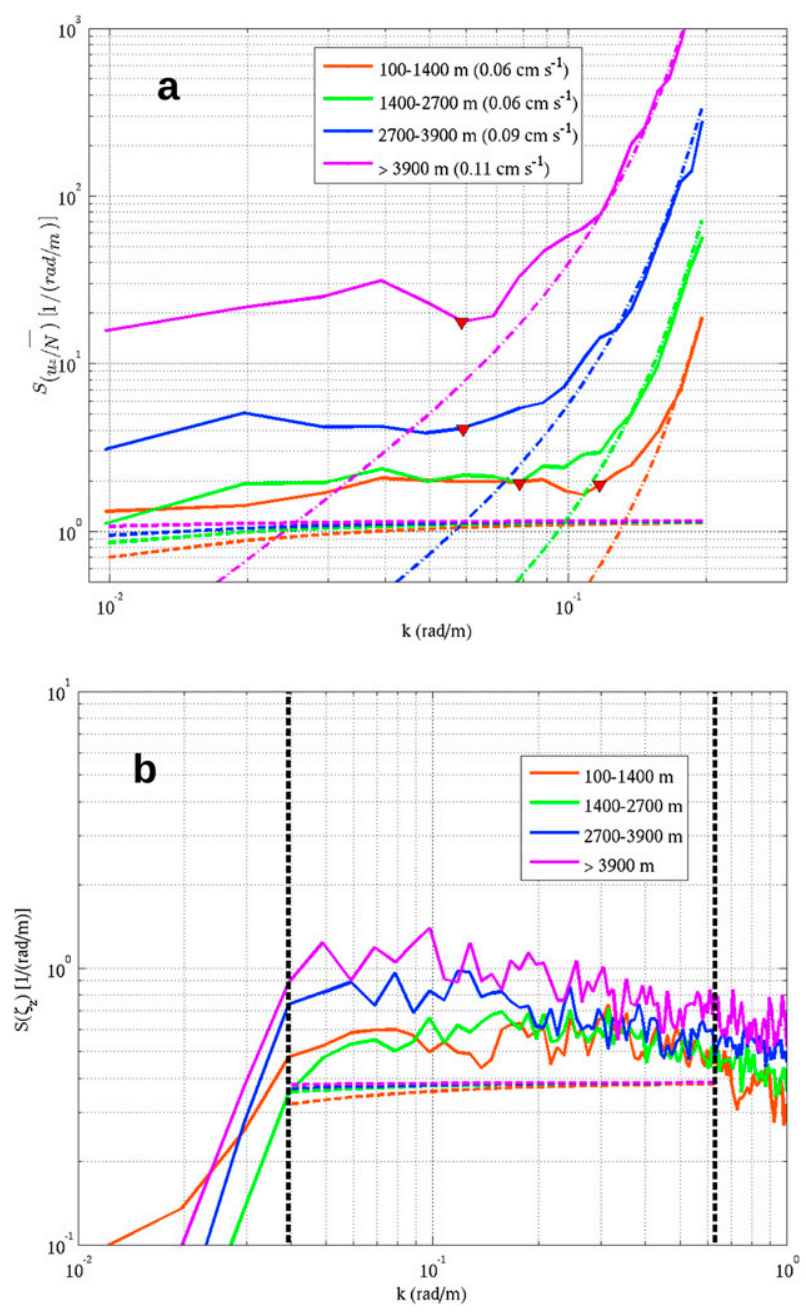

FIG. 4. (a) Buoyancy-normalized shear spectra by depth range (solid) and corresponding GM spectra (dashed). The single-ping error in velocity (dashed-dotted) is given in the legend $\left(\mathrm{cm} \mathrm{s}^{-1}\right)$ for each depth range, taking into account the depth-dependent number of pings (see Table 1 ). Red triangles located at $k_{\text {noise }}$ give the upper limit of spectral integration for each depth range. (b) Strain spectra by depth range (thick lines) and corresponding GM spectra (thin lines). Vertical dashed lines denote the lower and maximum upper limits to determine the strain variances.

above $1400 \mathrm{~m}_{\text {to }} 0.11 \mathrm{~m} \mathrm{~s}^{-1}$ deeper than $3900 \mathrm{~m}$ (Table 1). This is consistent with the single-ping error profile provided by the LADCP software for each station. This single-ping error increase with depth was likely due to a decrease in the number of scatterers with depth. To be consistent with the variable observed noise levels, a depth-dependent wavenumber $k_{\text {noise }}$ was chosen in the variance computation (Table 1).

A SBE 911 CTD was mounted on the carousel. CTD data were processed to provide 1-m vertical resolution density profiles consistent with World Ocean Circulation Experiment (WOCE) standards. Strain defined as
TABLE 1. Number of pings and single-ping error by depth range. Given the number of pings, the single-ping error was estimated as a fit to the corresponding shear spectrum (Fig. 4).

\begin{tabular}{cccc}
\hline \hline $\begin{array}{c}\text { Depth } \\
\text { range }(\mathrm{m})\end{array}$ & $\begin{array}{c}\text { No. of } \\
\text { pings }\end{array}$ & $\begin{array}{c}\text { Single-ping } \\
\text { error } \\
\left(\mathrm{m} \mathrm{s}^{-1}\right)\end{array}$ & $\begin{array}{c}k_{\text {noise }} \\
\left(\mathrm{rad} \mathrm{m}^{-1}\right)\end{array}$ \\
\hline$z<1400$ & 400 & 0.06 & $2 \pi / 52$ \\
$1400 \leq z<2700$ & 310 & 0.06 & $2 \pi / 79$ \\
$2700 \leq z<3900$ & 280 & 0.09 & $2 \pi / 106$ \\
$z \geq 3900$ & 250 & 0.11 & $2 \pi / 106$ \\
\hline
\end{tabular}

the vertical derivative of the isopycnal displacement $\zeta$ was estimated on the same vertical segments as the velocity shear. For a given downcast CTD profile, $\zeta$ were calculated from density fluctuations as $\zeta=\left(g / \rho_{0}\right)\left(\rho_{H P} / \overline{N^{2}}\right)$, where $\rho_{\mathrm{HP}}$ is the density profile filtered by a high-pass Butterworth filter with a cutoff wavelength of $200 \mathrm{~m}, \overline{N^{2}}$ is the segment-averaged buoyancy frequency, $\rho_{0}$ is a reference density, and $g$ is the standard gravity. The filter cutoff frequency was chosen to avoid contamination by background stratification (Kunze et al. 2006). The use of a local filter does not make any assumption on the shape of the density profile on the segment. Fitting a polynomial (e.g., quadratic fit for Kunze et al. 2006; linear fit for Lauderdale et al. 2008) to remove the low-frequency part from the density profile can produce in the thermocline increased high-frequency density fluctuations if the degree of the polynomial is not consistent with the shape of the density profile. Strain variances were computed as the integral of the isopycnal displacement spectra $S(\zeta)$ from $k_{\min }^{\zeta}$ to $k_{\max }^{\zeta}$, and $\left\langle\zeta_{z}^{2}\right\rangle=\int_{k_{\min }^{\zeta}}^{k_{\max }^{\zeta}} k^{2} S(\zeta) d k$, where $k_{\min }^{\zeta}=2 \pi / 160 \mathrm{rad} \mathrm{m}^{-1}$ and $k_{\max }^{\zeta}$ is the minimum of $2 \pi / 10 \mathrm{radm}^{-1}$ and a cutoff wavenumber for which the integrated strain variance equals 0.22 (i.e., the variance of the GM strain spectra integrated up to its cutoff wavenumber of $2 \pi / 10 \mathrm{rad} \mathrm{m}^{-1}$ ). The GM strain spectra were also integrated from $k_{\min }^{\zeta}$ to $k_{\text {max }}^{\zeta}$. Ensemble-averaged strain spectra exhibit levels that are $40 \%$ (upper water column) to $100 \%$ (at depth) larger than their corresponding GM levels (Fig. 4b).

Since wavenumber ranges for shear and strain variances are not equal, the shear-to-strain ratio is calculated as $R_{\omega}=\left[\left(\left\langle V_{z}^{2}\right\rangle /\left\langle V_{z \mathrm{GM}}^{2}\right\rangle\right) /\left(\left\langle\zeta_{z}^{2}\right\rangle /\left\langle\zeta_{z \mathrm{GM}}^{2}\right\rangle\right)\right] R_{\omega \mathrm{GM}}$, where both shear terms of the numerator are evaluated on the range $\left[k_{\min } ; k_{\max }\right]$, both strain terms of the denominator are evaluated on the range $\left[k_{\min }^{\zeta} ; k_{\max }^{\zeta}\right]$, and $R_{\omega \mathrm{GM}}=\left\langle V_{z G M}^{2}\right\rangle /\left(N^{2}\left\langle\zeta_{z \mathrm{GM}}^{2}\right\rangle\right)=3$.

\section{Results}

\section{a. Dissipation rates from microstructure}

The distribution of dissipation rates was first inferred from microstructure velocity shear data (Fig. 5a) and 

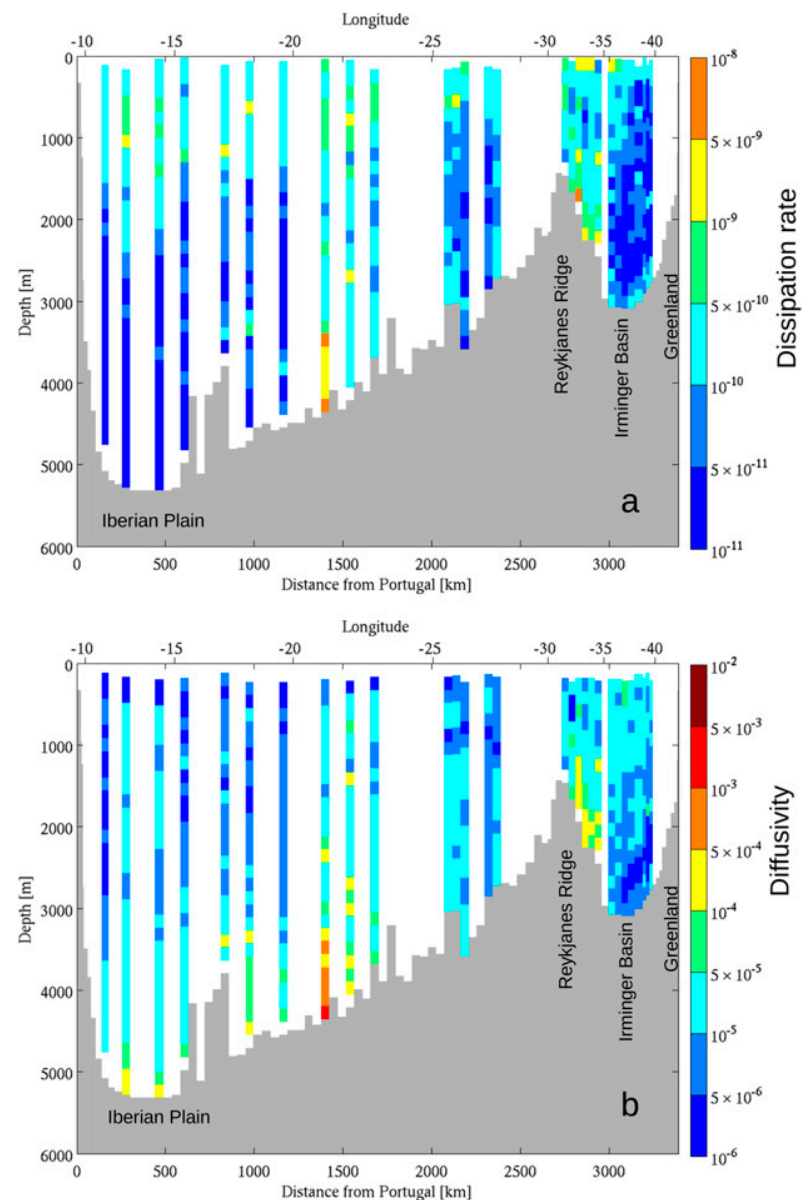

FIG. 5. (a) Dissipation rate profiles $\varepsilon_{\mathrm{vmp}}\left(\mathrm{W} \mathrm{kg}^{-1}\right)$ calculated from microstructure velocity shear data. (b) Corresponding diffusivity profiles $K_{\mathrm{vmp}}\left(\mathrm{m}^{2} \mathrm{~s}^{-1}\right)$. Bathymetry, as derived from CTD casts, is shaded in gray. Note the nonlinear color scales.

averaged on the same grid as the finestructure estimates (160-m-long bins; $\varepsilon_{\text {bin }}=\sum \varepsilon_{i} / N_{\text {bin }}$, where $\varepsilon_{\text {bin }}$ is the linear average of the $N_{\text {bin }}$ individual microstructure dissipation rate estimates $\varepsilon_{i}$ present in the bin). The weakest dissipation rate is found below $2000 \mathrm{~m}$ in the Iberian Abyssal Plain, to the north of the Azores-Biscay Rise and in the center of the Irminger basin with values mostly below $0.5 \times 10^{-10} \mathrm{~W} \mathrm{~kg}^{-1}$. Above $2000 \mathrm{~m}$, dissipation rates remain weak on the transect, usually around $1-5 \times$ $10^{-10} \mathrm{~W} \mathrm{~kg}^{-1}$ with a few peaks in the range $10-50 \times$ $10^{-10} \mathrm{~W} \mathrm{~kg}^{-1}$. The most intense values are found above the northwestern flank of the Reykjanes Ridge with values in the range of $5-100 \times 10^{-10} \mathrm{~W} \mathrm{~kg}^{-1}$ and at $48^{\circ} \mathrm{N}$, $21^{\circ} \mathrm{W}$ (blue arrow in Fig. 1) from $3400 \mathrm{~m}$ down to the seafloor at $4400 \mathrm{~m}$ with dissipation rates ranging from 10 to $100 \times 10^{-10} \mathrm{~W} \mathrm{~kg}^{-1}$.

To quantify the associated vertical diffusivity $K$, an equilibrium between production of turbulent kinetic energy by vertical velocity shear, increase in potential

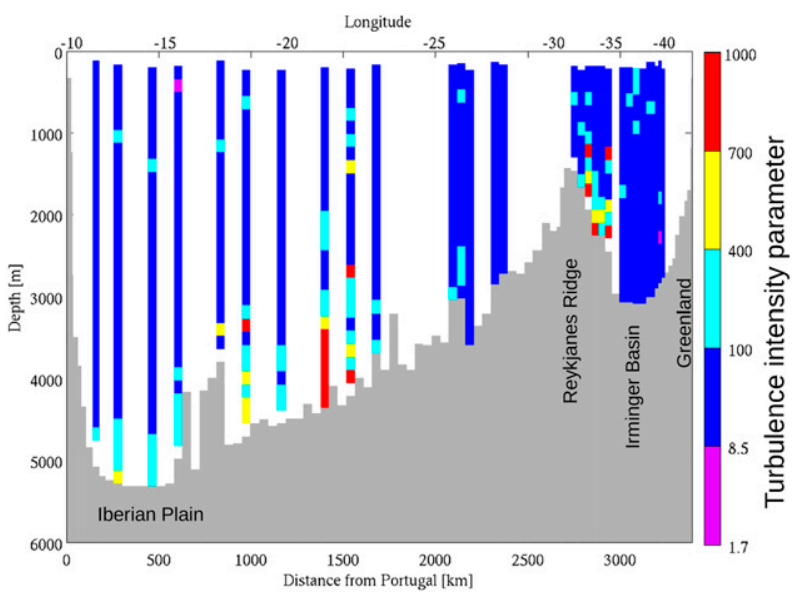

FIG. 6. Turbulence intensity parameter $\operatorname{Re}_{b}=\varepsilon /\left(\nu N^{2}\right)$. The color scale is nonlinear and emphasizes four mixing regimes (bounded by $1.7,8.5,400)$.

energy (mixing) and dissipation rate is often assumed leading to $K=\Gamma \varepsilon N^{-2}$ (Osborn 1980) with a constant mixing efficiency $\Gamma=0.2$. Shih et al. (2005) and more recently Bouffard and Boegman (2013) pointed to a dependency of the diffusivity upon the turbulent intensity parameter $\operatorname{Re}_{b}=\varepsilon /\left(\nu N^{2}\right)$. Depending on the value of $\mathrm{Re}_{b}$, four regimes for the diffusivity were identified: molecular $\left(\mathrm{Re}_{b}<1.7\right)$, buoyancy-controlled $\left(1.7<\mathrm{Re}_{b}<8.5\right)$, transitional $\left(8.5<\mathrm{Re}_{b}<400\right)$ and energetic $\left(\operatorname{Re}_{b}>400\right)$. The boundaries between the various regimes are given for a Prandtl number of 7 and are supported by field data (Bouffard and Boegman 2013). In the transitional regime, the Osborn relation with $\Gamma=0.2$ can be applied whereas in the energetic regime $K=4 \nu\left(\mathrm{Re}_{b}\right)^{1 / 2}$ is more appropriate. In the buoyancy-controlled (energetic) regime the use of the Osborn relation with $\Gamma=0.2$ underestimates (overestimates) the diffusivity. In this study, $\operatorname{Re}_{b}$ was derived from microstructure data (Fig. 6) and used to calculate the diffusivity. Most of the section belongs to the transitional regime for which the Osborn relation is valid. The energetic regime is found at a depth mainly at $21^{\circ} \mathrm{W}$ and on the northwestern flank of the Reykjanes Ridge.

The vertical diffusivities were usually below $0.5 \times$ $10^{-4} \mathrm{~m}^{2} \mathrm{~s}^{-1}$ on the transect, with values well below $0.11 \times$ $10^{-4} \mathrm{~m}^{2} \mathrm{~s}^{-1}$ in the upper $2000 \mathrm{~m}$ of the Iberian Abyssal Plain and at depth in the Irminger Basin (Fig. 5b). The two major regions with enhanced diffusivity concerned the bottom of the station at $21^{\circ} \mathrm{W}$ and $48^{\circ} \mathrm{N}$ where $K$ reaches $5 \times 10^{-4} \mathrm{~m}^{2} \mathrm{~s}^{-1}$ to $50 \times 10^{-4} \mathrm{~m}^{2} \mathrm{~s}^{-1}$ and the flank of the Reykjanes Ridge with moderate values ranging from 1 to $5 \times 10^{-4} \mathrm{~m}^{2} \mathrm{~s}^{-1}$. Note that for those two regions, using the Osborn relation with $\Gamma=0.2$ as done in most of previous studies would lead to a diffusivity larger 
by a factor of 3-4 along the Reykjanes Ridge and by a factor $4-8$ at $21^{\circ} \mathrm{W}$ and $48^{\circ} \mathrm{N}$.

\section{b. Comparison between finestructure and microstructure estimates of the dissipation rate}

Using the procedure described in section $2 b$, finescale estimates $\varepsilon_{\mathrm{G} 89}, \varepsilon_{\mathrm{P} 95}$, and $\varepsilon_{\mathrm{G} 03}$ are calculated using vertical profiles of velocity and density. The comparison of those estimates with the microstructure dissipation rate $\varepsilon_{\mathrm{vmp}}$ allows us to quantify how the different terms entering the parameterizations improve the consistency with $\varepsilon_{\mathrm{vmp}}$ (Fig. 7). Since the dissipation rate varies on several orders of magnitude and in order to compare equally the under- and overestimation of $\varepsilon_{\mathrm{vmp}}$, we defined the ratio $R_{\varepsilon}=\log _{10}\left(\varepsilon_{\text {finestructure }} / \varepsilon_{\mathrm{vmp}}\right)$, whose mean and standard deviation calculated for each of the tested parameterization is a measure of the bias between the parameterization and $\varepsilon_{\mathrm{vmp}}$ and of the dispersion of the estimates, respectively (Table 2).

The simplest parameterization, $\varepsilon_{\mathrm{G} 89}$, only agrees on average within an order of magnitude with $\varepsilon_{\mathrm{vmp}}$ (Fig. 7a) and clearly overestimates $\varepsilon_{\mathrm{vmp}}$. The mean $R_{\varepsilon}$ of 0.17 (Table 2) corresponds to an averaged overestimation by $50 \%\left(10^{0.17}=1.5\right)$. Weakly stratified regions are mostly responsible for this overestimation (Fig. 7a, dark blue dots). The exclusion of these regions where the buoyancy frequency $N^{2}$ falls below $10^{-7} \mathrm{~s}^{-2}$ improves the results and leads to an overestimation of $30 \%$. The standard deviation of the ratio is high (0.52) when all segments are considered and slightly decreases to 0.44 when weakly stratified regions are omitted. Taking the frequency modulation term $h\left(R_{\omega}\right)$ into account as done in the parameterization $\varepsilon_{\mathrm{P} 95}$ significantly improves the consistency of the parameterization with $\varepsilon_{\mathrm{vmp}}$ (Fig. 7b). The term $h\left(R_{\omega}\right)$ is lower than unity over most of the section (Figs. 8a,b). This strongly reduces the positive bias observed with $\varepsilon_{\mathrm{G} 89}$. The lowest values of $h\left(R_{\omega}\right)$ are found in weakly stratified regions where $h\left(R_{\omega}\right)$ is close to 0.2 . Most of the values larger than one are found in the upper $2000 \mathrm{~m}$ east of $21^{\circ} \mathrm{W}$ (distance to Portugal < $1500 \mathrm{~km}$ ). The mean of $R_{\varepsilon}$ falls close to zero $(-0.02)$ and its standard deviation decreases to a value of 0.39 with all segments taken into account. The added term $j(f / N)$ in the parameterization $\varepsilon_{\mathrm{G} 03}$ does not have a large impact on our dataset. Gregg et al. (2003) showed its strong impact at low latitudes. But it has also a significant influence in the case of a weak stratification. Indeed, this term decreases the estimated dissipation rate by a factor of 2-3 in the weakly stratified regions (Fig. 8c) of the Iberian Abyssal Plains. Elsewhere on the section, the term $j(f / N)$ tends to decrease the dissipation rates below $1500 \mathrm{~m}$ and to increase it above, with a maximum increase of $20 \%-30 \%$ in the stratified region of the North
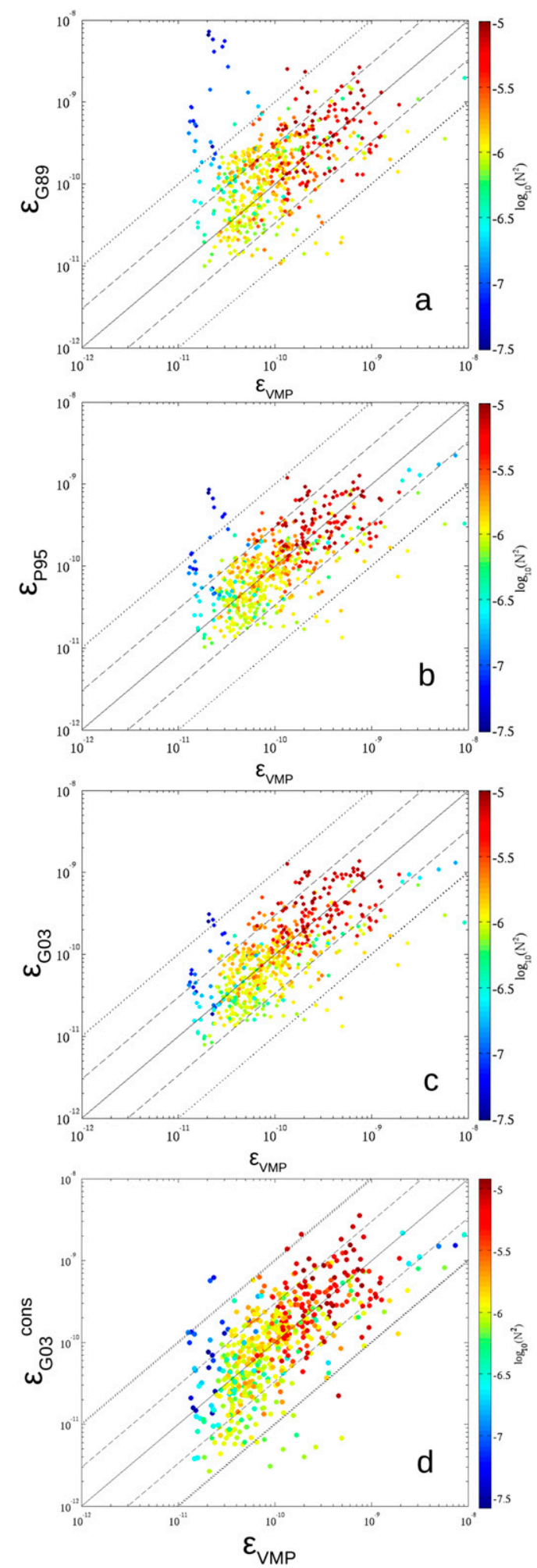

FIG. 7. Dissipation rate $\varepsilon_{\text {finestructure }}$ as a function of $\varepsilon_{\mathrm{vmp}}$. (a)-(d) Color scale denotes $\log _{10}\left(N^{2}\right)$ with $\varepsilon_{\text {finestructure }}=\varepsilon_{\mathrm{G} 89}, \varepsilon_{\mathrm{P} 95}, \varepsilon_{\mathrm{G} 03}$, $\varepsilon_{\mathrm{G} 03}$, respectively. Solid line denotes perfect agreement with microstructure, dashed lines represent a factor of 3 , and dotted lines represent a factor of 10 . 
TABLE 2. Averaged $\left(\left\langle R_{\varepsilon}\right\rangle\right)$ and standard deviation $\left(\sigma_{R \varepsilon}\right)$ of the magnitude of the ratio between the finestructure and the microstructure estimates of $\varepsilon$ with $R_{\varepsilon}=\log _{10}\left(\varepsilon_{\text {finestructure }} / \varepsilon_{\text {microstructure }}\right)$. Columns $F(m)$ gives the cumulative distribution $P\left(1 / m<\varepsilon_{\text {finestructure }} /\right.$ $\left.\varepsilon_{\text {microstructure }}<m\right)$ with $P$ denoting the probability that $\varepsilon_{\text {finestructure }} / \varepsilon_{\text {microstructure }}$ lies in the interval $(1 / m, m)$. Dissipation $\varepsilon_{\mathrm{G} 89}^{*}\left(\varepsilon_{\zeta}^{*}\right)$ is the same as $\varepsilon_{\mathrm{G} 89}\left(\varepsilon_{\zeta}\right)$ but restricted to the region where $\langle\omega\rangle>1.1 f$. $\varepsilon_{\mathrm{G} 03}^{\text {cons }}$ uses conservative fixed wavenumber bands to estimate shear and strain variances (see text for details).

\begin{tabular}{|c|c|c|c|c|c|c|}
\hline$\varepsilon_{\text {finestructure }}$ & $\left\langle R_{\varepsilon}\right\rangle$ & $\sigma_{R \varepsilon}$ & $F(1.5)(\%)$ & $F(2.5)(\%)$ & $F(3.5)(\%)$ & $F(4.5)(\%)$ \\
\hline$\varepsilon_{\mathrm{G} 89}$ & 0.17 & 0.52 & 30 & 60 & 76 & 85 \\
\hline$\varepsilon_{\mathrm{G} 89}^{*}$ & 0.10 & 0.41 & 32 & 64 & 80 & 89 \\
\hline$\varepsilon_{\text {P95 }}$ & -0.02 & 0.39 & 42 & 76 & 87 & 92 \\
\hline$\varepsilon_{\mathrm{G} 03}$ & -0.05 & 0.37 & 40 & 75 & 87 & 93 \\
\hline$\varepsilon_{\mathrm{G} 03}^{\text {cons }}$ & -0.04 & 0.44 & 36 & 66 & 80 & 88 \\
\hline$\varepsilon_{\zeta}$ & -0.12 & 0.48 & 39 & 72 & 83 & 89 \\
\hline$\varepsilon_{\zeta}^{*}$ & -0.04 & 0.35 & 42 & 77 & 88 & 93 \\
\hline
\end{tabular}

Atlantic Drift between $48^{\circ} \mathrm{N}, 21^{\circ} \mathrm{W}$ and the Reykjanes Ridge. Overall, the contribution of $j(f / N)$ slightly reduces the scatter in $\varepsilon_{\mathrm{G} 03}$ versus $\varepsilon_{\mathrm{vmp}}$ (Fig. 7c). The mean of $R_{\varepsilon}$ is -0.05 , slightly larger than for $\varepsilon_{\mathrm{P} 95}$, and its standard deviation is slightly improved with a value of 0.37 when all segments are taken into account (Table 2). Consistently, the cumulative distribution $F(m)=P(1 / m<$ $\varepsilon_{\text {finestructure }} / \varepsilon_{\mathrm{vmp}}<m$ ), with $P$ being the probability that $\varepsilon_{\text {finestructure }} / \varepsilon_{\mathrm{vmp}}$ lies in the interval $[1 / m, m]$, gives better results for $\varepsilon_{\mathrm{P} 95}$ than for $\varepsilon_{\mathrm{G} 89}$ (Table 2). The cumulative distributions of $\varepsilon_{\mathrm{P} 95} / \varepsilon_{\mathrm{vmp}}$ and $\varepsilon_{\mathrm{G} 03} / \varepsilon_{\mathrm{vmp}}$ are similar. The fact that the standard deviation is nonetheless better for $\varepsilon_{\mathrm{G} 03}$ than for $\varepsilon_{\mathrm{P} 95}$ is associated with the fewer extreme points in the $\varepsilon_{\mathrm{G} 03}$ parameterization. The probability density function (PDF) of the ratio $\varepsilon_{\mathrm{G} 03} / \varepsilon_{\mathrm{vmp}}$ is symmetric about unity (Fig. 9). For $3 \%$ of the segments, the ratio $\varepsilon_{\mathrm{G} 03} / \varepsilon_{\mathrm{vmp}}$ presents extreme values larger than 7 or weaker than $1 / 7$ ( $4 \%$ for the ratio $\left.\varepsilon_{\mathrm{P} 95} / \varepsilon_{\mathrm{vmp}}\right)$.

The regional distribution of the ratio $\varepsilon_{\mathrm{G} 03} / \varepsilon_{\mathrm{vmp}}$ does not provide a clear picture (Fig. 10). Some specific features stand out: $\varepsilon_{\mathrm{G} 03}$ tends to overestimate $\varepsilon_{\mathrm{vmp}}$ in the upper $1000 \mathrm{~m}$ of the stratified waters south of the Reykjanes Ridge and to underestimate $\varepsilon_{\mathrm{vmp}}$ in the upper $1500 \mathrm{~m}$ of the weakly stratified waters of the Irminger basin; in the deepest part of the transect, $\varepsilon_{\mathrm{G} 03}$ overestimates $\varepsilon_{\mathrm{vmp}}$ in the poorly stratified waters of the Iberian Abyssal Plain $(z>4500 \mathrm{~m})$ and in the deepest part of the Irminger Basin, while it underestimates $\varepsilon_{\mathrm{vmp}}$ from $21^{\circ}$ to $26^{\circ} \mathrm{W}$ and on the northwestern flank of the Reykjanes Ridge.

To test the sensitivity of $\varepsilon_{\mathrm{G} 03}$ to the spectral ranges chosen to calculate the shear and strain variances, another estimate $\varepsilon_{\mathrm{G} 03}^{\text {cons }}$ is presented that also uses Gregg et al. (2003) finescale parameterization with "conservative" choices taken from Kunze et al. (2006): segments are $320 \mathrm{~m}$ long, strain (shear) variances are calculated using a [30-150]m $([150-320] \mathrm{m})$ wavenumber range. The new estimate $\varepsilon_{\mathrm{G} 03}^{\text {cons }}$ exhibits a larger dispersion than $\varepsilon_{\mathrm{G} 03}$, especially for observed dissipation rates $\varepsilon_{\mathrm{vmp}}<1 \times 10^{-10} \mathrm{~W} \mathrm{~kg}^{-1}$ and buoyancy frequencies $N<1.3 \times 10^{-3} \mathrm{~s}^{-1}$ (Fig. 7d; Table 2). A closer inspection of the results shows that most of the increase in the dispersion comes from the shear variance estimate being restricted to a shorter wavenumber range. Indeed, only two spectral components are used in the range $[150-320] \mathrm{m}$ to calculate the shear variance for $\varepsilon_{\mathrm{G} 03}^{\text {cons }}$, which produces a larger uncertainty than for $\varepsilon_{\mathrm{G} 03}$. The moderate reduction in the range of wavenumbers for the strain variance only slightly increases the dispersion but not significantly ( $\varepsilon_{\mathrm{G} 03}^{\text {cons }}$ dispersion $\sigma_{R \varepsilon}$ increased by 0.02 compared with $\left.\varepsilon_{\mathrm{G} 03}\right)$.

\section{c. Dissipation rates and diffusivity from finestructure on the full transect}

To get a complete view of the distribution of the dissipation rate on the OVIDE transect, the parameterization $\varepsilon_{\mathrm{G} 03}$ is applied to all the CTD-LADCP casts and the diffusivity is derived following Bouffard and Boegman (2013; Fig. 11). For buoyancy frequencies weaker than $1.4 \mathrm{~s}^{-1}$ (potential temperature $\theta<4.5^{\circ} \mathrm{C}$ ), the dissipation rate usually reaches weak values, $\varepsilon_{\mathrm{G} 03}<10^{-10} \mathrm{~W} \mathrm{~kg}^{-1}$. High values of the dissipation rate are found above the bottom at some locations as the microstructure data suggested. The southeastern flank of the Reykjanes Ridge, for which no microstructure data were available because of a heavy sea state, shows the same moderate intensification as that found on the northwestern flank. A moderate intensification is also visible along the Greenland slope.

Since the diffusivity scales as $\varepsilon_{\mathrm{G} 03} N^{-2}$, the diffusivity distribution is somehow opposite to that of the dissipation. The largest values are found at a depth where the stratification is weak. The most intense values are found in a 1000-m-thick layer above the seafloor from the Iberian Plain up to $21^{\circ} \mathrm{W}$ (from 1 to $10 \times 10^{-4} \mathrm{~m}^{2} \mathrm{~s}^{-1}$ ), around the Reykjanes Ridge $\left(1-5 \times 10^{-4} \mathrm{~m}^{2} \mathrm{~s}^{-1}\right)$ and above $1200 \mathrm{~m}$ on the Greenland slope $\left(1-5 \times 10^{-4} \mathrm{~m}^{2} \mathrm{~s}^{-1}\right)$. Elsewhere on the transect, the diffusivity falls below $5 \times 10^{-5} \mathrm{~m}^{2} \mathrm{~s}^{-1}$. 

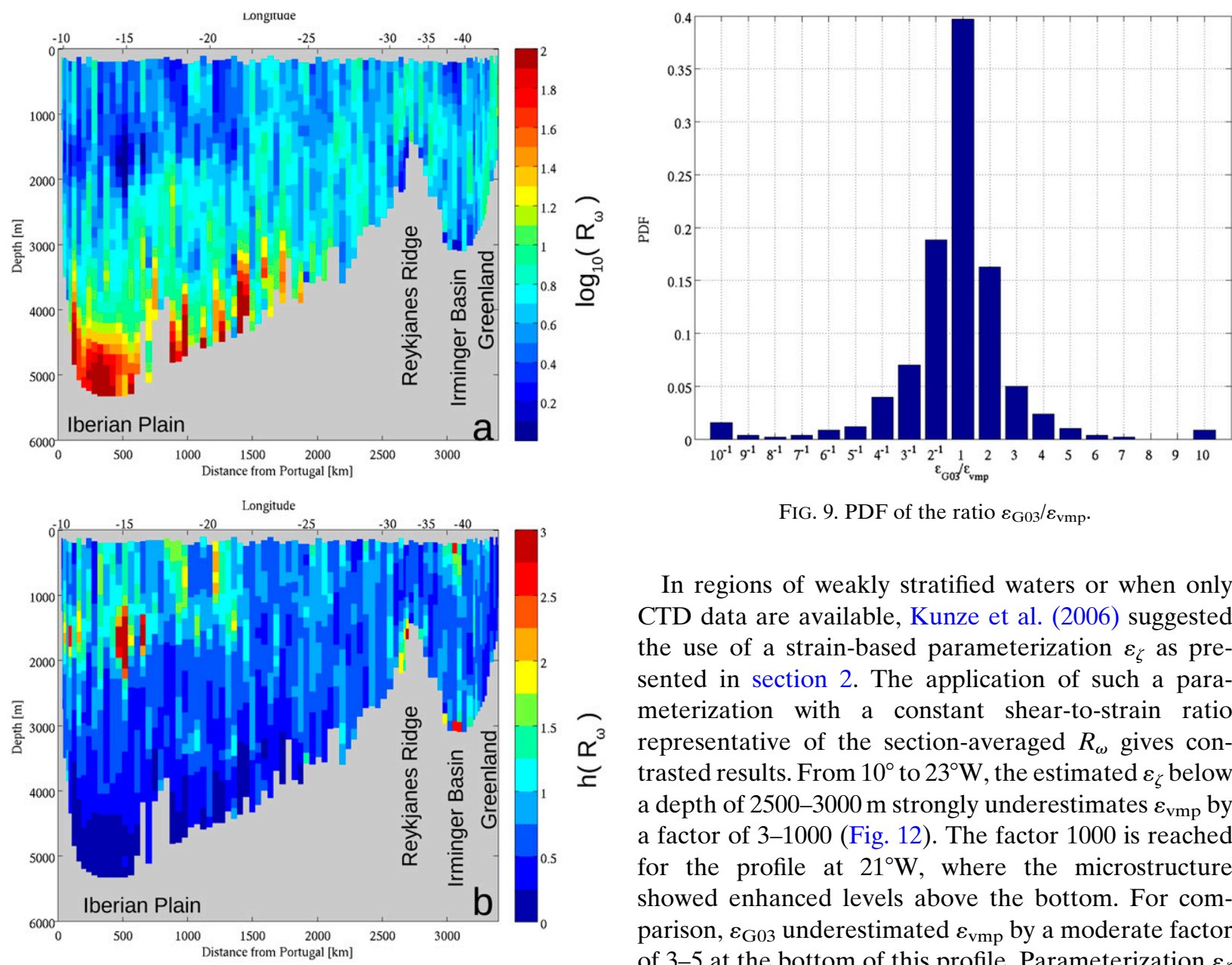

FIG. 9. PDF of the ratio $\varepsilon_{\mathrm{G} 03} / \varepsilon_{\mathrm{vmp}}$.

In regions of weakly stratified waters or when only CTD data are available, Kunze et al. (2006) suggested the use of a strain-based parameterization $\varepsilon_{\zeta}$ as presented in section 2. The application of such a parameterization with a constant shear-to-strain ratio representative of the section-averaged $R_{\omega}$ gives contrasted results. From $10^{\circ}$ to $23^{\circ} \mathrm{W}$, the estimated $\varepsilon_{\zeta}$ below a depth of 2500-3000 m strongly underestimates $\varepsilon_{\mathrm{vmp}}$ by a factor of 3-1000 (Fig. 12). The factor 1000 is reached for the profile at $21^{\circ} \mathrm{W}$, where the microstructure showed enhanced levels above the bottom. For comparison, $\varepsilon_{\mathrm{G} 03}$ underestimated $\varepsilon_{\mathrm{vmp}}$ by a moderate factor of 3-5 at the bottom of this profile. Parameterization $\varepsilon_{\zeta}$ completely misses the intensification of the dissipation rate at $21^{\circ} \mathrm{W}$ (cf. Figs. 5a, 12). Note that the region between $10^{\circ}$ and $23^{\circ} \mathrm{W}$ is weakly stratified at depth, which hinders good estimates of the strain from one instantaneous vertical density profile. Moreover, the strainbased parameterization is expected to underestimate dissipation rates there, since this region is biased toward low frequencies (i.e., high values of $R_{\omega}$; Fig. 8a), which means weak signatures on the strain. In contrast, $\varepsilon_{\zeta}$ overestimates $\varepsilon_{\mathrm{vmp}}$ by a factor of 2-10 above $1500-$ $2000 \mathrm{~m}$ and south of the Reykjanes Ridge (Fig. 12b), where $R_{\omega}$ is relatively low (region biased toward higher frequencies). Again, $\varepsilon_{\mathrm{G} 03}$ provides a better estimate despite a similar bias in this region. North of the Reykjanes Ridge $\varepsilon_{\zeta}$ and $\varepsilon_{\mathrm{G} 03}$ are similar. The averaged ratio $\log _{10}\left(\varepsilon_{\zeta} / \varepsilon_{\mathrm{vmp}}\right)$ is -0.12 with a standard deviation of 0.48 (Table 2). Those statistics are close to that obtained with $\varepsilon_{\mathrm{G} 89}$ that similarly assumes a constant shear-tostrain ratio $\left[h\left(R_{\omega}\right)=1<=>R_{\omega}=R_{\omega}^{\mathrm{GM}}=3\right]$ together with $j(f / N)=1$. However, $\varepsilon_{\mathrm{G} 89}$ produces reasonable estimates where $\varepsilon_{\mathrm{vmp}}$ was enhanced at depth. From this comparison, we conclude that the use of $\varepsilon_{\zeta}$ based on term $h\left(R_{\omega}\right)$, and (c) latitude/buoyancy frequency modulation term $j(f / N)$ used in the finescale parameterizations $\varepsilon_{\mathrm{P} 95}$ and $\varepsilon_{\mathrm{G} 03}$. 


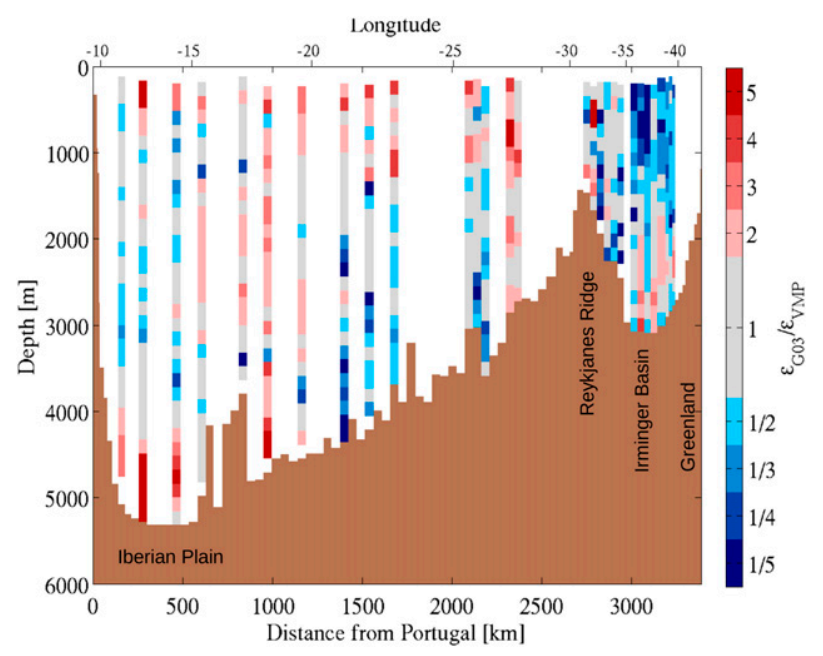

FIG. 10. Distribution of the ratio $\varepsilon_{\mathrm{G} 03} / \varepsilon_{\mathrm{vmp}}$.

a single density profile with a constant $R_{\omega}$ has to be used with care and may miss important features and produce regionally strong biases even when a regional value of $R_{\omega}$ is chosen.

To gain more insight into the frequency content of the internal wave field, an estimate of the wave-field-averaged frequency $\langle\omega\rangle$ is diagnosed from $R_{\omega}$ [see Polzin et al. 1995, Eq. (15)]. For the whole transect, $\langle\omega\rangle$ is close to the inertial frequency (between $f$ and $2 f$ ) apart from a small region located between $14^{\circ}$ and $16^{\circ} \mathrm{N}$ and at $1200-2200-\mathrm{m}$ depth for which $\langle\omega\rangle$ is nearly 3 times as large as $f$ (Fig. 13a). Hibiya et al. (2012) used another approach to estimate the relative contribution of $\alpha$, the "high" $(2 f-N)$ frequency band, and of $\beta$, the "low" $(f-2 f)$ frequency band, to the observed shear and strain variances. The ratio $\beta / \alpha$ measures the spectral distortion from the GM spectra. Applied to our dataset, we found that the high-frequency band is close to the GM level $(\alpha<2)$ apart from the southeastern flank of the Reykjanes Ridge $(6<\alpha<10)$ and in a small region centered at $15^{\circ} \mathrm{N}$ and $1700 \mathrm{dbar}(4<\alpha<7)$. The contribution of the low-frequency band is usually close to the GM level $(\beta<$ 2 ) above $2000 \mathrm{dbar}$. The largest values $(\beta>6)$ are found at depth below $3500 \mathrm{dbar}$ to the south of $26^{\circ} \mathrm{N}$ and on the northwestern flank of the Reykjanes Ridge. Elsewhere, the low-frequency band is only moderately higher than the GM prescription $(2<\beta<5)$. Interestingly, the ratio $\beta / \alpha$ shows a good consistency with $\langle\omega\rangle$ (Fig. 13b). The high-frequency band tends to dominate $(\beta / \alpha<1 / 3)$ in a few patches above $2000 \mathrm{~m}$ located south of $22^{\circ} \mathrm{N}$. At depth, the ratio $\beta / \alpha$ is also smaller than $1 / 3$ on the southern flank of the Reykjanes Ridge but not on its northern flank. Elsewhere, the low-frequency band mostly dominates $(\beta / \alpha>4)$. Note that $\langle\omega\rangle$ and $\beta / \alpha$ are indirect estimates of the averaged frequency content of
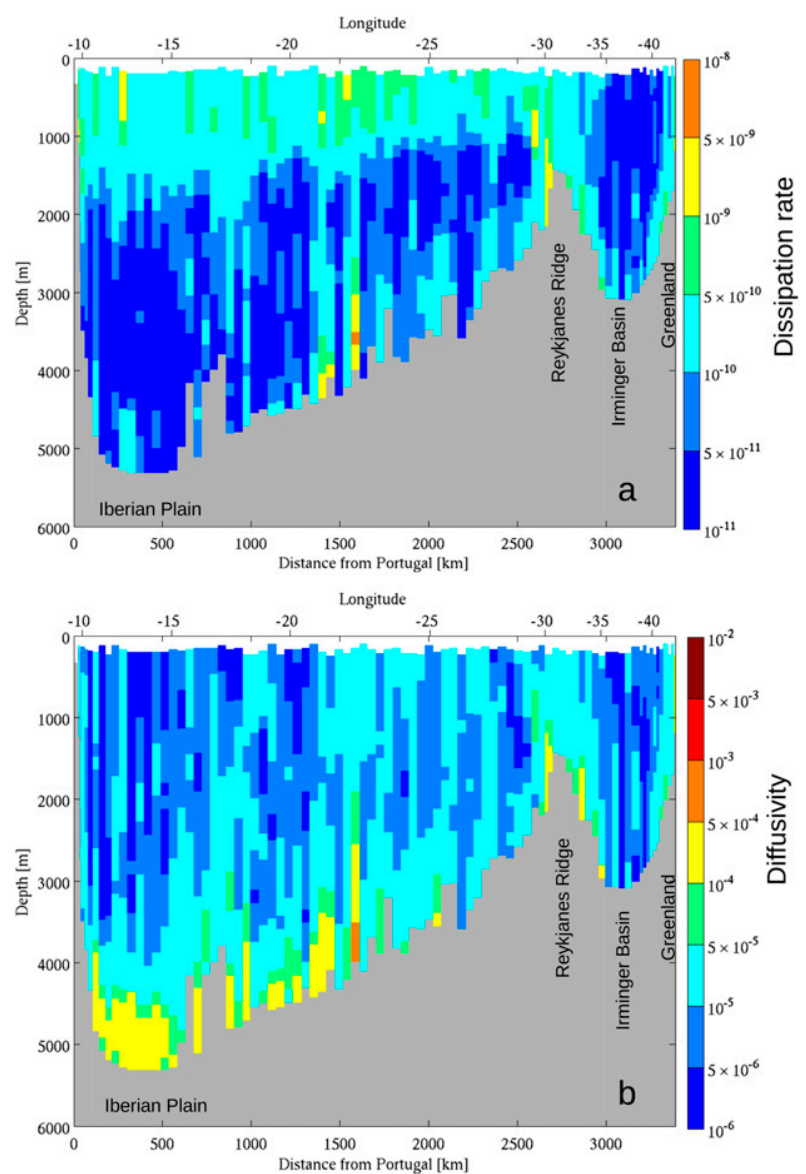

FIG. 11. (a) Dissipation rate profiles $\varepsilon_{\mathrm{G} 03}\left(\mathrm{~W} \mathrm{~kg}^{-1}\right)$ calculated from the finestructure of CTD-LADCP data. (b) Corresponding diffusivity profiles $K_{\mathrm{G} 03}\left(\mathrm{~m}^{2} \mathrm{~s}^{-1}\right)$. Bathymetry, as derived from CTD casts, is shaded in gray. The nonlinear color scales are the same as in Fig. 5.

the wave field subject to uncertainties. Several criteria based on either $\alpha, \beta, \beta / \alpha$, or $\langle\omega\rangle$ have been tested to define a validity threshold above which $\varepsilon_{\zeta}$ remains consistent with $\varepsilon_{\mathrm{vmp}}$, thus avoiding the large discrepancy found at depth in the weakly stratified waters. The only acceptable criterion found is to consider the use of $\varepsilon_{\zeta}$ only when $\langle\omega\rangle>1.1 f$, with $f$ being the Coriolis parameter (Fig. 13a, white line). Using this criterion, the statistics of the ratio $\varepsilon_{\zeta} / \varepsilon_{\mathrm{vmp}}$ are not significantly different from those of $\varepsilon_{\mathrm{G} 03} / \varepsilon_{\mathrm{vmp}}$ (Table 2, line $\varepsilon_{\zeta}^{*}$ ). This confirms that the sole isopycnal strain data diagnosed from the CTD cannot be used to quantify dissipation rates in a nearinertial wave field with $\langle\omega\rangle<1.1 f$ and in the presence of a weakly stratified environment. No criterion was found that improves the statistics of the ratio $\varepsilon_{\mathrm{G} 89} / \varepsilon_{\mathrm{vmp}}$ to the level of $\varepsilon_{\mathrm{G} 03} / \varepsilon_{\mathrm{vmp}}$, although restricting the calculation to either $\langle\omega\rangle>1.1 \mathrm{f}$ or $\beta<10$ improves by $4 \%$ the cumulative distribution while still showing a mean positive bias $(+25 \%)\left(\right.$ Table 2 , line $\left.\varepsilon_{\mathrm{G} 89}^{*}\right)$. 

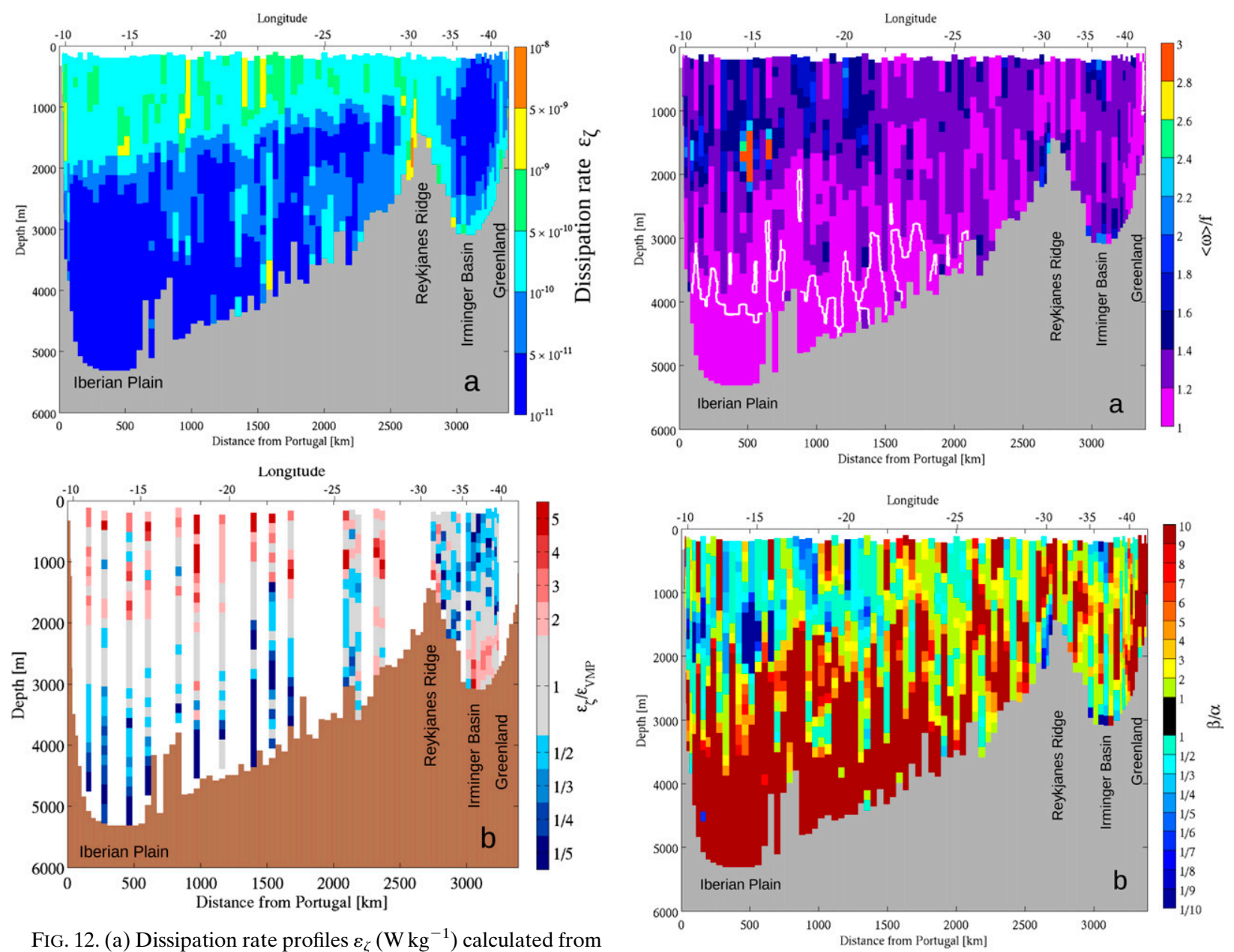

FIG. 12. (a) Dissipation rate profiles $\varepsilon_{\zeta}\left(\mathrm{W} \mathrm{kg}^{-1}\right)$ calculated from the finestructure of CTD data with a constant shear-to-strain ratio of 5.2. (b) Distribution of the ratio $\varepsilon_{\zeta} / \varepsilon_{\mathrm{vmp}}$.

\section{Summary and discussion}

For our dataset, the largest overestimation of $\varepsilon_{\mathrm{vmp}}$ by the finescale estimate appears in the Iberian Abyssal Plain below a depth of $4400 \mathrm{~m}$ (Fig. 10). In this region of weak stratification $(N \approx 3 f)$, both the terms $h\left(R_{\omega}\right)$ and $j(f / N)$ contribute to improve the consistency of $\varepsilon_{\mathrm{G} 03}$ with $\varepsilon_{\mathrm{vmp}}$ (see the evolution of the dark blue dots from Fig. 7a to Fig. 7c). However, some of the segments remain strongly inconsistent (by a factor of 10). From an analysis of the shear-to-strain ratio $R_{\omega}$, Kunze et al. (2006) argued that weakly stratified waters are associated with velocity profiles that are potentially strongly contaminated by noise, since the number of scatterers there is often low. They reported very high values of $R_{\omega}$ ranging from 30 to more than 1000 for $N<4.5 \times 10^{-4} \mathrm{~s}^{-1}$ (see their. Below $4000 \mathrm{~m}$ in the Iberian Plain, $\mathrm{R}_{\omega}$ also exhibits values ranging from 30 to 300 for a buoyancy frequency $N<3.2 \times 10^{-4} \mathrm{~s}^{-1}$ (Fig. 8a). The noise associated with those deep profiles $(z>3900 \mathrm{~m})$ is more

FIG. 13. (a) Ratio $\langle\omega\rangle / f$ of the averaged internal wave frequency scaled by the inertial frequency; the white line denotes the threshold $\langle\omega\rangle=1.1 f$. (b) Ratio $\beta / \alpha$ of the low-to-high wavenumber band contribution to the observed shear and strain variances.

intense by a factor of 2 compared to depths $z<2700 \mathrm{~m}$ and is clearly visible for wavenumbers larger than $0.07 \mathrm{rad} \mathrm{m}^{-1}$ (Table 1; Fig. 4). At low wavenumbers $\left(k<0.05 \mathrm{rad} \mathrm{m}^{-1}\right)$, however, the spectral shape of the buoyancy-normalized shear is flat as it is at shallower depths (Fig. 4). This means that if noise exists on velocity profiles for $k<0.05 \mathrm{rad} \mathrm{m}^{-1}$, then it coincidentally has the same $k^{-2}$ dependence before changing to white noise for $k>0.07 \mathrm{rad} \mathrm{m}^{-1}$. Although one cannot exclude that noise is responsible for the overestimation of the dissipation rate in those regions, one could also argue that the scaling of observed shear by the traditional GM shear may not be appropriate for weakly stratified waters. Indeed, Gerkema and Shrira (2005) and Gerkema and Exarchou (2008) showed that nontraditional effects (effects of the Coriolis terms proportional to the cosine of latitude) can significantly change internal wave properties in weakly stratified waters. 
Shallower than $3500 \mathrm{~m}$, the averaged transect value of $R_{\omega}$ is 5.2 (standard deviation of 3 ), nearly twice the GM value of 3 . Thus, there is on average more energy in near-inertial frequencies in our dataset than there is in the GM model (there is no peak of energy at tidal frequencies in the GM model). Kunze et al. (2006) found an averaged $R_{\omega}$ of 7 for various sections distributed over the Atlantic, Pacific and Indian Oceans. The ratio of the low $(f-2 f)$ to high $(2 f-N)$ wavenumber band contribution to the observed shear and strain variances confirms that at depth spectra are biased toward low frequencies compared to GM spectra. This is somewhat expected, since GM spectra does not take the tidal forcing into account. Interestingly the Reykjanes Ridge shows a significant cross-ridge contrast, the northwestern flank being biased toward low frequencies, while the southeastern flank is biased toward high frequencies. Over the Emperor seamount chain, Hibiya et al. (2012) also found some regions where $\beta$ and $\alpha$ dominate at depth (e.g., their profiles $\mathrm{H} 3$ and $\mathrm{H} 1$, respectively). They attributed the bias toward high frequencies to tidal interactions with topographic features, which also possibly occur on the southeastern flank of the Reykjanes Ridge. Additional temporal measurements from moorings are needed to clearly quantify whether the contrast as diagnosed from $\beta / \alpha$ and $\langle\omega\rangle$ is really significant. One can, however, note from altimetric data that there is also a cross-ridge asymmetry in the mesoscale eddy kinetic energy distribution with much higher levels to the northwest than to the southeast of the ridge. Nikurashin and Ferrari (2010) report enhanced near-inertial motions due to lee-wave generation by geostrophic currents, a process that is possibly at play to the north of the ridge.

On most parts of the section, the finescale parameterization $\varepsilon_{\mathrm{G} 03}$ is consistent with the microstructure dissipation rate $\varepsilon_{\mathrm{vmp}}$. This suggests that most of the turbulent activity recorded in this dataset is due to the internal wave field. Over $75 \%$ of the transect, the agreement is within a factor of 2.5 and almost $95 \%$ within a factor 4.5. Although we did not average the segments into bins as done in Polzin et al. (1995), which would reduce the scatter, those statistics are consistent with previous published studies (e.g., Polzin et al. 1995, 2002; Gregg et al. 2003). The use of the frequency-based correction term $h\left(R_{\omega}\right)$ improves the consistency as Polzin et al. (1995) found. The latitude/buoyancy frequency term slightly improves the parameterization, especially for weakly stratified waters. On average, the parameterization $\varepsilon_{\mathrm{G} 03}$ tends to underestimate the microstructure dissipation rate by $11 \%$. Most of the transect takes place away from internal wave generation sites (away from the surface and away from rough topography). The environment is then favorable for the comparison with finescale parameterizations based on the GM model, which is representative of the internal wave field away from boundaries.

Apart from a few locations near the topography, diffusivity remains weak. It is lower than $1 \times 10^{-5} \mathrm{~m}^{2} \mathrm{~s}^{-1}$ over $44 \%$ of the transect and lower than $5 \times 10^{-5} \mathrm{~m}^{2} \mathrm{~s}^{-1}$ over $90 \%$ of the transect. The picture emerging from this dataset is consistent with the finescale estimate of the dissipation rate along the A16N WOCE hydrographic line in the eastern North Atlantic for the same latitude range (Kunze et al. 2006, their Fig. 11). Stöber et al. (2008) reported frequent occurrences of enhanced diffusivities larger than $1 \times 10^{-4} \mathrm{~m}^{2} \mathrm{~s}^{-1}$ on the Greenland slope off Cape Farewell (Eirik Ridge) for profiles located over isobaths ranging from 2700 up to $1100 \mathrm{~m}$ (their Fig. 4e). The part of our transect above the Greenland slope is located $100 \mathrm{~km}$ eastward and only exhibits such enhanced diffusivities for slopes shallower than $1150 \mathrm{~m}$ despite similar velocity amplitudes of the boundary current (maxima of $0.2-0.3 \mathrm{~m} \mathrm{~s}^{-1}$ ), which extends down to the isobath $2500 \mathrm{~m}$. Consistently, Lauderdale et al. (2008) reported bottom-intensified diffusivities frequently beyond $10 \times 10^{-4} \mathrm{~m}^{2} \mathrm{~s}^{-1}$ around the Eirik Ridge and a factor of 5-10 less for a transect located on the Greenland slope near ours. Note that Lauderdale et al. (2008) used a strain-based parameterization with a constant "conservative" shear-to-strain ratio of 7.6 $\left[h_{\zeta}\left(R_{\omega}\right)=3\right.$ in Eq. (4)]. At $48^{\circ} \mathrm{N}$ and from $22^{\circ}$ to $14^{\circ} \mathrm{W}$, Walter et al. (2005) applied the shear variance [Eq. (3)] to a set of LADCP and CTD profiles to calculate dissipation and diffusivity. They found enhanced diffusivities that are systematically in the range of 10-100 $\times$ $10^{-4} \mathrm{~m}^{2} \mathrm{~s}^{-1}$ near the bottom and that they gradually decreased to $1 \times 10^{-4} \mathrm{~m}^{2} \mathrm{~s}^{-1}$ at a distance of more than $1000 \mathrm{~m}$ above the seafloor. Such a strong intensification widely distributed in the eastern basin was partly attributed to the roughness of the bathymetry due to the proximity of the Mid-Atlantic Ridge. They also pointed out that from $40^{\circ}$ to $50^{\circ}$ of latitude, subinertial wave energy can be trapped (Gerkema and Shrira 2005) and lead to such intense diffusivities. In the region of our transect located in the same eastern basin, we indeed observe an intensification of turbulent diffusivities but 1) it is one to two orders of magnitude less important near the bottom (at most $1-5 \times 10^{-4} \mathrm{~m}^{2} \mathrm{~s}^{-1}$; Fig. 11a) than Walter et al. (2005) found, and 2) it is not associated with an intensification of the dissipation rate (Fig. 11b) but results from the weak values of the buoyancy frequency $N$ used to calculated diffusivities from the Osborn (1980) relation. East of $21^{\circ} \mathrm{W}$, our microstructure data do not show an intensification of the dissipation rate at depth either. Consistent with our study, Kunze et al. (2006) only 
find a few spots of elevated diffusivity that hardly reach $1 \times 10^{-4} \mathrm{~m}^{2} \mathrm{~s}^{-1 \mathrm{i}}$ in the same deep basin. We believe that part of the discrepancy observed in this region at depth comes from the fact that Walter et al. (2005) did not use the scaling term function of the buoyancy frequency $\left\{\cosh ^{-1}(N / f) /\left[\cosh ^{-1}\left(N_{0} / f_{30}\right)\right]\right\}$ in $j(f / N)$ [Eq. (3)]. Our dataset showed that for weakly stratified waters, this term decreased the finescale estimate of the dissipation rates and diffusivity, and improved the consistency with microstructure observations of the dissipation rates. Thus, our microstructure data and our finestructure shear/strain dataset do not support the idea of a basinwide intensification of the turbulent diffusivities at depth because of wave trapping between $40^{\circ}$ and $50^{\circ} \mathrm{N}$. The canonical globally averaged value of order $10^{-4} \mathrm{~m}^{2} \mathrm{~s}^{-1}$ needed to maintain the abyssal stratification (Munk 1966) is only reached on the flank of the Reykjanes Ridge and in the region around $21^{\circ} \mathrm{W}$. Enhanced dissipation rates and diffusivity above the Reykjanes Ridge are potentially sustained by enhanced levels of semidiurnal tidal energy observed above the Reykjanes Ridge (van Haren 2007) and by breaking of lee waves generated by bottom geostrophic flows above this rough topography (Nikurashin and Ferrari 2011).

Acknowledgments. The microstructure profiler was funded by the French Agence Nationale de la Recherche (ANR) through Grant ANR-JC05_50690 and by the French Institute for Marine Science (IFREMER). B. Ferron and H. Mercier were supported by the French National Center for Scientific Research (CNRS), F. Kokoszka by a doctoral grant from the Ministère de la Rechercher et de l'Enseignement Supérieur, and P. Lherminier by IFREMER.

\section{REFERENCES}

Bouffard, D., and L. Boegman, 2013: A diapycnal diffusivity model for stratified environmental flows. Dyn. Atmos. Oceans, 61-62, 14-34, doi:10.1016/j.dynatmoce.2013.02.002.

Cairns, J. L., and G. O. Williams, 1976: Internal wave observations from a midwater float, 2. J. Geophys. Res., 81, 1943-1950, doi:10.1029/JC081i012p01943.

Daae, K. L., I. Fer, and E. P. Abrahamsen, 2009: Mixing on the continental slope of the southern Weddell Sea. J. Geophys. Res., 114, C09018, doi:10.1029/2008JC005259.

Dillon, T. M., 1982: Vertical overturns: A comparison of Thorpe and Ozmidov length scales. J. Geophys. Res., 87, 9601-9613, doi:10.1029/JC087iC12p09601.

Firing, E., and R. Gordon, 1990: Deep ocean acoustic Doppler current profiling. Proceedings of the IEEE Fourth Working Conference on Current Measurement, IEEE, 192-201, doi:10.1109/CURM.1990.110905.

Fischer, J., and M. Visbeck, 1993: Deep velocity profiling with selfcontained ADCPs. J. Atmos. Oceanic Technol., 10, 764-773, doi:10.1175/1520-0426(1993)010<0764:DVPWSC >2.0.CO;2.
Frants, M., G. M. Damerell, S. T. Gille, K. J. Heywood, J. MacKinnon, and J. Sprintall, 2013: An assessment of density-based finescale methods for estimating diapycnal diffusivity in the Southern Ocean. J. Atmos. Oceanic Technol., 30, 2647-2661, doi:10.1175/JTECH-D-12-00241.1.

Garrett, C., and W. Munk, 1975: Space-time scales of internal waves: A progress report. J. Geophys. Res., 80, 291-297, doi:10.1029/JC080i003p00291.

Gerkema, T., and V. I. Shrira, 2005: Near-inertial waves on the "non-traditional" $\beta$ plane. J. Geophys. Res., 110, C01003, doi:10.1029/2004JC002519.

—_, and E. Exarchou, 2008: Internal-wave properties in weakly stratified layers. J. Mar. Res., 66, 617-644, doi:10.1357/ 002224008787536817.

Goodman, L., E. R. Levine, and R. G. Lueck, 2006: On measuring the terms of the turbulent kinetic energy budget from an AUV. J. Atmos. Oceanic Technol., 23, 977-990, doi:10.1175/ JTECH1889.1.

Gregg, M. C., 1989: Scaling turbulent dissipation in the thermocline. J. Geophys. Res., 94, 9686-9698, doi:10.1029/JC094iC07p09686.

_- 1999: Uncertainties and limitations in measuring $\epsilon$ and $\chi_{\mathrm{T}}$. J. Atmos. Oceanic Technol., 16, 1483-1490, doi:10.1175/ 1520-0426(1999)016<1483:UALIMA > 2.0.CO;2.

_ T. B. Sanford, and D. P. Winkel, 2003: Reduced mixing from the breaking of internal waves in equatorial ocean waters. Nature, 422, 513-515, doi:10.1038/nature01507.

Hibiya, T., and M. Nagasawa, 2004: Latitudinal dependence of diapycnal diffusivity in the thermocline estimated using a finescale parameterization. Geophys. Res. Lett., 31, L01301, doi:10.1029/2003GL017998.

—, N. Furuichi, and R. Robertson, 2012: Assessment of finescale parameterizations of turbulent dissipation rates near mixing hotspots in the deep ocean. Geophys. Res. Lett., 39, L24601, doi:10.1029/2012GL054068.

Hogg, N., P. Biscaye, W. Gardner, and W. J. Schmitz Jr., 1982: On transport and modification of Antarctic Bottom Water in the Vema Channel. J. Mar. Res., 40 (Suppl.), 231-263.

Kunze, E., E. Firing, J. M. Hummon, T. K. Chereskin, and A. M. Thurnherr, 2006: Global abyssal mixing inferred from lowered ADCP shear and CTD strain profiles. J. Phys. Oceanogr., 36, 1553-1576, doi:10.1175/JPO2926.1.

Lauderdale, J. M., S. Bacon, A. C. Naveira Garabato, and N. P. Holiday, 2008: Intensified turbulent mixing in the boundary current system of southern Greenland. Geophys. Res. Lett., $\mathbf{3 5}$, L04611, doi:10.1029/2007GL032785.

Ledwell, J. R., A. J. Watson, and C. S. Law, 1993: Evidence for slow mixing across the pycnocline from an open-ocean tracer release. Nature, 364, 701-702, doi:10.1038/364701a0.

— E. T. Montgomery, K. L. Polzin, L. C. St. Laurent, R. W. Schmitt, and J. M. Toole, 2000: Evidence for enhanced mixing over rough topography in the abyssal ocean. Nature, 403, 179182, doi:10.1038/35003164.

Levine, E. R., and R. G. Lueck, 1999: Turbulence measurement from an autonomous underwater vehicle. J. Atmos. Oceanic Technol., 16, 1533-1544, doi:10.1175/1520-0426(1999)016<1533: TMFAAU $>2.0 . \mathrm{CO} ; 2$.

MacKinnon, J. A., T. M. S. Johnston, and R. Pinkel, 2008: Strong transport and mixing of deep water through the Southwest Indian Ridge. Nat. Geosci., 1, 755-758, doi:10.1038/ngeo340.

Macoun, P., and R. Lueck, 2004: Modeling the spatial response of the airfoil shear probe using different sized probes. J. Atmos. Oceanic Technol., 21, 284-297, doi:10.1175/1520-0426(2004)021<0284: MTSROT $>2.0 . \mathrm{CO} ; 2$. 
Mercier, H., and Coauthors, 2014: Variability of the meridional overturning circulation at the Greenland-Portugal OVIDE section from 1993 to 2010. Prog. Oceanogr., doi:10.1016/ j.pocean.2013.11.001, in press.

Moum, J. N., M. C. Gregg, R. C. Lien, and M. E. Carr, 1995: Comparison of turbulence kinetic energy dissipation rate estimates from two ocean microstructure profilers. J. Atmos. Oceanic Technol., 12, 346-366, doi:10.1175/1520-0426(1995)012<0346: COTKED $>2.0 . \mathrm{CO} ; 2$.

Munk, W. H., 1966: Abyssal recipes. Deep-Sea Res. Oceanogr. Abstr., 13, 707-730, doi:10.1016/0011-7471(66)90602-4.

_ , and C. Wunsch, 1998: Abyssal recipes II: Energetics of tidal and wind mixing. Deep-Sea Res. I, 45, 1977-2010, doi:10.1016/ S0967-0637(98)00070-3.

Nasmyth, P. V., 1970: Ocean turbulence. Ph.D. thesis, University of British Columbia, 69 pp.

Naveira Garabato, A. C., K. I. C. Oliver, A. J. Watson, and M.-J. Messias, 2004a: Turbulent diapycnal mixing in the Nordic seas. J. Geophys. Res., 109, C12010, doi:10.1029/2004JC002411.

— , K. L. Polzin, B. A. King, K. J. Heywood, and M. Visbeck, 2004b: Widespread intense turbulent mixing in the Southern Ocean. Science, 303, 210-213, doi:10.1126/science.1090929.

Nikurashin, M., and R. Ferrari, 2010: Radiation and dissipation of internal waves generated by geostrophic motions impinging on small-scale topography: Application to the Southern Ocean. J. Phys. Oceanogr., 40, 2025-2042, doi:10.1175/ 2010JPO4315.1.

—_, and - 2011: Global energy conversion rate from geostrophic flows into internal lee waves in the deep ocean. Geophys. Res. Lett., 38, L08610, doi:10.1029/2011GL046576.

Oakey, N. S., 1982: Determination of the rate of dissipation of turbulent energy from simultaneous temperature and velocity shear microstructure measurements. J. Phys. Oceanogr., 12, 256-271, doi:10.1175/1520-0485(1982)012<0256: DOTROD $>2.0 . \mathrm{CO} ; 2$.

Osborn, T. R., 1980: Estimates of the local rate of vertical diffusion from dissipation measurements. J. Phys. Oceanogr., 10, 83-89, doi:10.1175/1520-0485(1980)010<0083:EOTLRO > 2.0.CO;2.

Polzin, K. L., J. M. Toole, and R. W. Schmitt, 1995: Finescale parameterization of turbulent dissipation. J. Phys. Oceanogr., 25, 306328, doi:10.1175/1520-0485(1995)025<0306:FPOTD>2.0.CO;2.

, E. Kunze, J. Hummon, and E. Firing, 2002: The finescale response of lowered ADCP velocity profiles. J. Atmos. Oceanic Technol., 19, 205-224, doi:10.1175/1520-0426(2002)019<0205: TFROLA $>2.0 . \mathrm{CO} ;$.
Sheen, K. L., and Coauthors, 2013: Rates and mechanisms of turbulent dissipation and mixing in the Southern Ocean: Results from the Diapycnal and Isopycnal Mixing Experiment in the Southern Ocean (DIMES). J. Geophys. Res. Oceans, 118, 2774-2792, doi:10.1002/jgrc.20217.

Shih, L. H., J. R. Koseff, G. N. Ivey, and J. H. Ferziger, 2005: Parameterization of turbulent fluxes and scales using homogeneous sheared stably stratified turbulence simulations. J. Fluid Mech., 525, 193-214, doi:10.1017/S0022112004002587.

Smith, W. H. F., and D. T. Sandwell, 1997: Global seafloor topography from satellite altimetry and ship depth soundings. Science, 277, 1956-1962, doi:10.1126/science.277.5334.1956.

Stöber, U., M. Walter, C. Mertens, and M. Rhein, 2008: Mixing estimates from hydrographic measurements in the Deep Western Boundary Current of the North Atlantic. Deep-Sea Res. I, 55, 721-736, doi:10.1016/j.dsr.2008.03.006.

Thorpe, S. A., 1977: Turbulence and mixing in a Scottish loch. Philos. Trans. Roy. Soc. London, A286, 125-181, doi:10.1098/ rsta.1977.0112.

Thurnherr, A. M., 2012: The finescale response of lowered ADCP velocity measurements processed with different methods. J. Atmos. Oceanic Technol., 29, 597-600, doi:10.1175/ JTECH-D-11-00158.1.

Tian, J., Q. Yang, and W. Zhao, 2009: Enhanced diapycnal mixing in the South China Sea. J. Phys. Oceanogr., 39, 3191-3203, doi:10.1175/2009JPO3899.1.

van Haren, H., 2007: Inertial and tidal shear variability above Reykjanes Ridge. Deep-Sea Res. I, 54, 856-870, doi:10.1016/ j.dsr.2007.03.003.

Visbeck, M., 2002: Deep velocity profiling using lowered acoustic Doppler current profilers: Bottom track and inverse solutions. J. Atmos. Oceanic Technol., 19, 794-807, doi:10.1175/ 1520-0426(2002)019<0794:DVPULA > 2.0.CO;2.

Walter, M., C. Mertens, and M. Rhein, 2005: Mixing estimates from a large-scale hydrographic survey in the North Atlantic. Geophys. Res. Lett., 32, L13605, doi:10.1029/2005GL022471.

Waterman, S., A. C. Naveira Garabato, and K. L. Polzin, 2013: Internal waves and turbulence in the Antarctic Circumpolar Current. J. Phys. Oceanogr., 43, 259-282, doi:10.1175/ JPO-D-11-0194.1.

Wijesekera, H., L. Padman, T. Dillon, M. Levine, C. Paulson, and R. Pinkel, 1993: The application of internal-wave dissipation models to a region of strong forcing. J. Phys. Oceanogr., 23, 269-286, doi:10.1175/1520-0485(1993)023<0269: TAOIWD $>2.0 . \mathrm{CO} ; 2$ 